\title{
SCHISTOSOMAL EPIDIDYMITIS
}

\author{
LEONARDO S. ALVES, BERNADO P. S. ASSIS, MÁRCIA M. B. REZENDE \\ Procriar Instituto de Urologia, Belo Horizonte, Minas Gerais, Brazil
}

\begin{abstract}
Epididymitis is a frequent inflammatory process. It is related to sexually transmitted diseases, urinary tract infections by E. coli, or scrotal trauma. We describe the case of a Caucasian 32year old man, who presented scrotal pain for 3 months, with difficult management with medication. Testis was normal; however, the left epididymis was extremely painful and hardened. Following the unsuccessful use of analgesic and anti-inflammatory medication, a left epididymectomy was performed, with resolution of the pain.

The pathological examination showed the presence of chronic inflammatory process associated with eggs of the parasite Schistosoma mansoni in the resected epididymis. Patient evolved without pain in the post-operative period and was medicated with a single dose of oxamniquine after etiologic confirmation.
\end{abstract}

Key words: epididymis; epididymitis; Schistosoma mansoni

Int Braz J Urol. 2004; 30: 413-5

\section{INTRODUCTION}

Epididymitis is an inflammatory process that affects the epididymis. It occurs around the testis and can appear at any age. Clinical presentations of epididymitis are most frequently related to sexually transmitted diseases, trauma and contamination by surgical instruments. The present work reports the case of a patient with chronic epididymal pain and hardening due to infestation by the parasite Schistosoma mansoni.

\section{CASE REPORT}

Patient W.A.O., 32 years old, born in Belo Horizonte, Minas Gerais, Brazil, developed a painful scrotal process, with difficult management, 3 months earlier. He denied trauma, recent surgical procedures (vasectomy 2 years earlier) or suspected sexual activity.

On physical examination, a hardened and painful left epididymis was observed. Ipsilateral testis and spermatic cord were normal. Scrotal ultrasound demonstrated only an increase in echogenicity, characteristic of chronic inflammatory process. After the unsuccessful use of analgesic and anti-inflammatory drugs, we chose to perform unilateral epididymectomy, with the patient's consent. The procedure had no intercurrences, and during the surgery, we observed hardening of the entire epididymis, without testicular involvement. The patient's pain resolved shortly after surgery. Histopathological study detected granulomatous chronic inflammatory process due to the presence of Schistosoma mansoni eggs (Figure-1). After the diagnosis, the patient's contact with a lagoon infested by the parasite was confirmed. Patient received a single dose of the antiparasitic drug oxamniquine. 


\section{COMMENTS}

Epididymitis is a common inflammatory process frequently involving the ipsilateral testis as well, a condition known as orchiepididymitis (1). The acute presentation constitutes the most common cause of acute scrotum in adults. Isolated epididymitis can occur at all ages, and is related to bacterial infection (E. coli, N. gonorrhea, H. influenza, Chlamydia trachomatis, Thichomonas vaginalis). Other etiologic causes are contamination by endoscopic instruments, testicular torsion, trauma, vasectomy, orchiopexy, etc.

Etiologic agents such as M. tuberculosis, Brucella, fungi (coccidiodomycosis and blastomycosis) and parasites such as Schistosoma mansoni, are less frequently diagnosed due to technical difficulties $(1,2)$. In these cases, the confirmation is achieved only by histopathological study. Most frequently, the contamination occurs by the canalicular route, through the deferens vas, where germs from the urogenital tract ascend to the epididymis (1).

The diagnosis of epididymitis can be made from the anamnesis and physical examination. Through correlation with the patient's age range, it is possible to deduce the etiologic agent. Viral and bacterial infections are common until sexual initiation. From this period up to 40 years old, gonococcus and
Chlamydia are the major responsible pathogens, while after this age, E. coli is the most frequently found agent. The physical examination can determine if the process is acute (enlargement and pain) or chronic (hardening). Imaging methods, as well as blood, urine and feces tests, can help to determine the etiology of the symptoms.

Schistosomiasis mansoni is an endemic parasitosis in Brazil caused by a trematode, the Schistosoma mansoni. It usually parasitizes the venous system presenting tropism to the hepatic portal system. In this system, the inferior mesenteric vein, liver and spleen are the most frequently affected sites (3). Contamination by Schistosoma mansoni occurs by hematogenic route according to the parasite's life cycle (3). When a person comes in contact with water that is infested by schistosomes, the parasites in the form of cercariae penetrate the skin and reach blood or lymph circulation. At this moment, they can be destroyed by the immunological system or reach the peripheral venous circulation. The parasite couple goes towards the hemorrhoidal plexus at the time of oviposition, and can go to the seminal plexus as well, which would explain the present case (3). When affected by schistosoma, the epididymis increases in size due to the inflammatory process, similarly to other affected organs. A granulomatous inflammatory

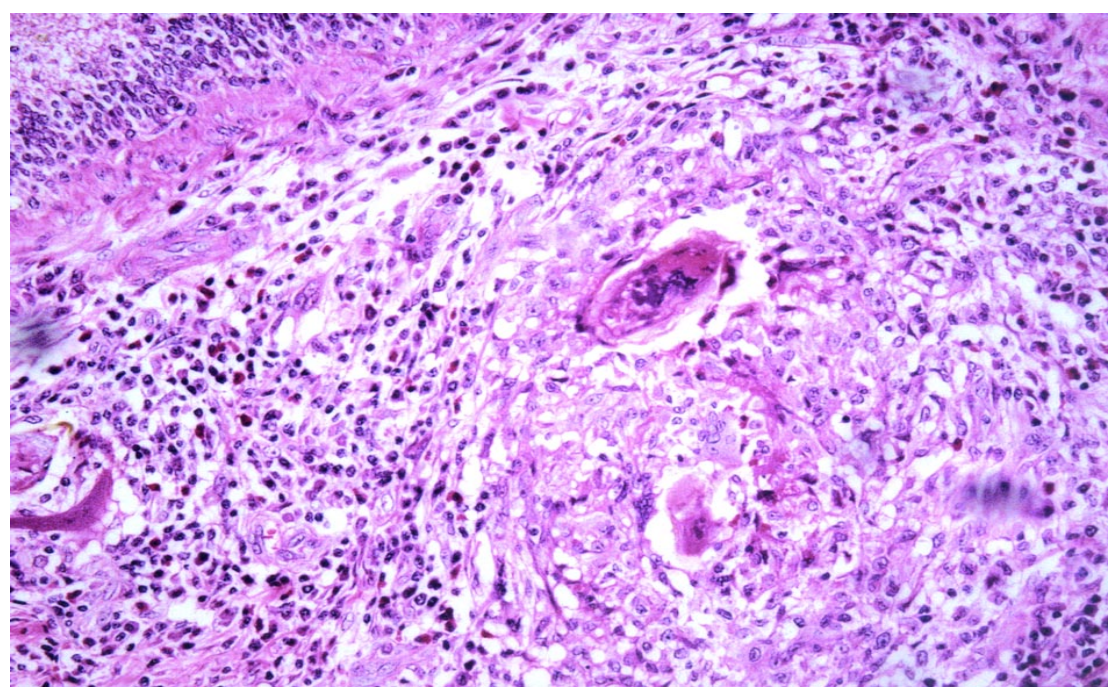

Figure 1 - Photomicrography of epididymis slide showing granulomatous chronic inflammation with Langhans-type giant cell reaction, presenting a large number of eosinophils around spiculated structures similar to Schistosoma mansoni eggs (HE, X400). 
pattern with Langhans-type giant cell reaction, presenting a large number of eosinophilic cells around spiculated structures (eggs) is characteristic in this process (Figure-1).

The difficulty for etiologic diagnostic in this case was because the only sign of disease was a hardened epididymis and pain. The pathological result, until then unexpected, draw our attention to the clinical fault in the anamnesis, which failed to investigate the contact of the patient with "still waters", since schistosomiasis mansoni is an endemic disease in Brazil.

$\overline{\text { Prof. Lúcia Porto Fonseca Castro performed }}$
the pathological analysis.

\section{REFERENCES}

1. Costa, M: Orquiepididimites In: Guia Prático de Urologia, SBU, São Paulo, BG Cultural Editora. 1999; pp. 139-46.

2. Kaufman, JJ: Current Urologic Therapy. Philadelphia, WB Saunders Co. 1980; pp. 357-60.

3. Pessoa SB: Parasitologia Médica. Rio de Janeiro, Guanabara Koogan. 1958; p. 471-558.

Received: April 04, 2004

Accepted after revision: July 29, 2004

\section{Correspondence address:}

Dr. Leonardo de Souza Alves

Rua Gonçalves Dias, 142, Funcionários

Belo Horizonte, MG, 30140-090, Brazil

Tel.: + 5531 3225-0907

E-mail: procriar@bol.com.br 